\title{
Isolation and Screening of Multifunctional Plant Growth Promoting Rhizobacteria (PGPR) from Onion Rhizosphere (Allium cepa)
}

\section{Sonali Phale}

Department of Microbiology, MES Abasaheb Garware College, Pune, Maharashtra, India

*Corresponding author: Sonali Phale, Department of Microbiology, MES Abasaheb Garware College, Pune, Maharashtra, India, Tel: +8446504860; E-mail: sonaliphale21@gmail.com

Received date: July 30, 2018; Accepted date: August 07, 2018; Published date: August 12, 2018

Copyright: (c) 2018 Phale S. This is an open-access article distributed under the terms of the Creative Commons Attribution License, which permits unrestricted use, distribution, and reproduction in any medium, provided the original author and source are credited.

\begin{abstract}
Plant Growth Promoting Rhizobacteria (PGPR) can enhance the growth and productivity of plants through direct and indirect mechanisms. In this study, rhizobacteria were isolated from onion rhizosphere and their plant growth promoting activities were studied. The investigations of activities include: nitrogen fixation, phosphate solubilization, zinc mobilization, hydrogen cyanide and indole-3-acetic acid production abilities. Plant growth promoting rhizobacteria (PGPR) influence plant health and productivity by various ways. It can be summarized that the isolated multifunctional PGPR strains may have potential to be successful bio-inoculants for onion plant.
\end{abstract}

Keywords: Rhizobacteria; Rhizosphere; PGPR; Phosphate solubilization; Zinc mobilization; Nitrogen fixation

\section{Introduction}

Plant roots in the soil show profuse activity relative to the bulk soil. $\mathrm{pH}$, nutrients and exudates gradients changing as distance from the root increases [1]. This region of gradients in chemical and physical factors strongly influenced by the presence of plant roots and characterized by high rates of microbial population and activity is increasingly referred to as the rhizosphere. In fact, in 1904, Hiltner first defined the rhizosphere as that zone of soil in which the micro flora is influenced by plant roots [2].

Microorganisms are essential for maintenance of sustainable ecosystems and bio-diversity. Colonization of the plant root system is the very first step in nearly all interactions between plants and soilborne microbes. Plant growth promoting rhizobacteria (PGPR) influences plant health and productivity by various ways. A good selection of a PGPR strain requires understanding of bacterial communities colonizing the rhizosphere. To date, only limited information exists on microbial diversity and dynamic of population in agricultural soil [3]. The properties related to the PGP character are auxin production, nitrogen fixation, phytopathogen antagonism, cyanogenesis, phosphate solubilization and amino cyclopropane carboxylic acid (ACC) deaminase activity [4]. Indian economy is agricultural based. But the use of chemical fertilizer has led to a considerable increase in agricultural productivity. The use of PGPR gives better way to replace chemical fertilizer, pesticides. PGPR help in the disease control in plants. PGPR especially if they are inoculated on the seed before planting, can establish themselves on the crop roots this is possible with onion crop as it is re-planted. Beneficial soil microbes are studied and exploited for the development of sustainable agriculture. The purpose of manipulating crop rhizosphere microbial populations by inoculation of beneficial bacteria to increase plant growth. It has shown considerable promise in laboratory and greenhouse studies. The important environmental benefits of this approach, leading to a reduction in the use of agricultural chemicals and the fit with sustainable management practices, are driving force of this project.

The objectives of this study are to isolate bacteria from onion root rhizosphere, to isolate plant growth promoting rhizobacteria with multifunctional ability and to evaluate and analyze growth promoting ability under in-vitro conditions.

\section{Materials and Methods}

\section{Sampling}

The sample used to isolate Rhizobacteria is rhizosphere soil sample around Onion roots. Onion root washed with water to remove adhering soil particles. Roots washed in saline suspension taken in 5 sterile tubes one after the another aseptically. Washing collected and mixed thoroughly with the help of Vortex mixture.

\section{Isolation}

10\% Nutrient Agar, Pikovaskaya medium, Solid Extract Agar, Norris broth were used for isolation. Loop full of each washing aseptically spread on the sterile $10 \%$ Nutrient agar plates i.e., $10 \%$ Salt added to Nutrient Agar and on 10\% Soil Extract Agar plates. Incubated these plates for 48 hours at Room temperature. Growth observed in the form of number of different colonies on both the medium (Figure 1). Then transferred those colonies on Nutrient Agar slant with appropriate label and stored them in refrigerator for further tests.

\section{Screening}

Phosphate solubilizing capacity of each isolate checked by making grids on the Pikovskaya's agar medium (Table 1), the activity was checked by spot inoculating the isolates. Zone of clearance taken to be the positive test (Figure 2).

Pikovskaya's Agar is suspend 31.3 grams in $1000 \mathrm{ml}$ distilled water. Heat to boiling to dissolve the medium completely and sterilize by autoclaving at $15 \mathrm{lbs}$ pressure $\left(121^{\circ} \mathrm{C}\right)$ for 15 minutes. Mix well and pour into sterile Petri plates. 
Citation: Phale S (2018) Isolation and Screening of Multifunctional Plant Growth Promoting Rhizobacteria (PGPR) from Onion Rhizosphere (Allium cepa). J Bioprocess Biotech 8: 335. doi:10.4172/2155-9821.1000335

Page 2 of 4

\begin{tabular}{|l|l|}
\hline Ingredients & Gms/Litre \\
\hline Yeast Extract & 0.5 \\
\hline Dextrose & 10.0 \\
\hline Tri-Calcium Phosphate & 5.0 \\
\hline Ammonium sulphate & 0.5 \\
\hline Potassium chloride & 0.2 \\
\hline Magnesium sulphate & 0.1 \\
\hline Manganese sulphate & 0.0001 \\
\hline Ferrous sulphate & 0.0001 \\
\hline Agar & 15.0 \\
\hline
\end{tabular}

Table 1: Pikovskaya's Agar Composition.

$\mathrm{Zn}$ solubilizing property of isolates checked by adding zinc oxide in Nutrient Agar as per above procedure (Figure 3).

Test for nitrogen fixation was done by inoculating isolates in Nitrogen free medium (Table 2) that is Norris broth. Turbidity after incubation was the positive test. Norris Glucose Nitrogen free Broth is suspend 12.5 grams in $1000 \mathrm{ml}$ distilled water. Heat just to boiling. Sterilize by autoclaving at $15 \mathrm{lbs}$ pressure $\left(121^{\circ} \mathrm{C}\right)$ for 15 minutes. Mix well and dispense as desired.

\begin{tabular}{|l|l|}
\hline Ingredients & Gms/Litre \\
\hline Glucose & 10.0 \\
\hline Dipotassium phosphate & 1.0 \\
\hline Magnesium sulphate & 0.2 \\
\hline Calcium carbonate & 1.0 \\
\hline Sodium chloride & 0.25 \\
\hline Sodium molybdate & 0.005 \\
\hline Ferrous sulphate & 0.1 \\
\hline Final pH & $7.0 \pm 0.2$ \\
\hline
\end{tabular}

Table 2: Norris Glucose Nitrogen free Broth Composition.

Then isolate was tested for Indole Acetic Acid Production. IAA or Indole acetic acid is plant growth promoting hormone. For the experiment, each isolate was inoculated in Tryptone broth. After incubation $1 \mathrm{ml}$ of Broth was taken in Eppendorf tube and allowed to centrifuge for $2 \mathrm{~min}$ at about $15000 \mathrm{rpm}$. The supernatant was then taken and to it Salkowaskys Reagent was added. The reaction between reagent and IAA produced by isolate produced the characteristic red color which is taken as confirm Positive test.

The last test performed was to detect whether the Isolate can produce $\mathrm{HCN}$ gas or not. For the test the organism was grown on Glycerin containing medium and then on the upper part of test tube the Picric acid paper was placed. The tubes were then incubated at Room Temperature for 48 hours. The reaction of HCN Gas with picric acid imparts red color to the Paper. This was taken as positive test (Figure 4).

\section{Results and Discussion}

The isolates $1,3,5,30,31,38,45,46$ are of interest and show good plant growth promoting activity (Table 3 ).

However, the cultures 14, 15, 22, 26, 27, 44 are of no use because they show property of production of toxic $\mathrm{HCN}$ gas which can inhibit the growth of beneficial organisms in the vicinity.

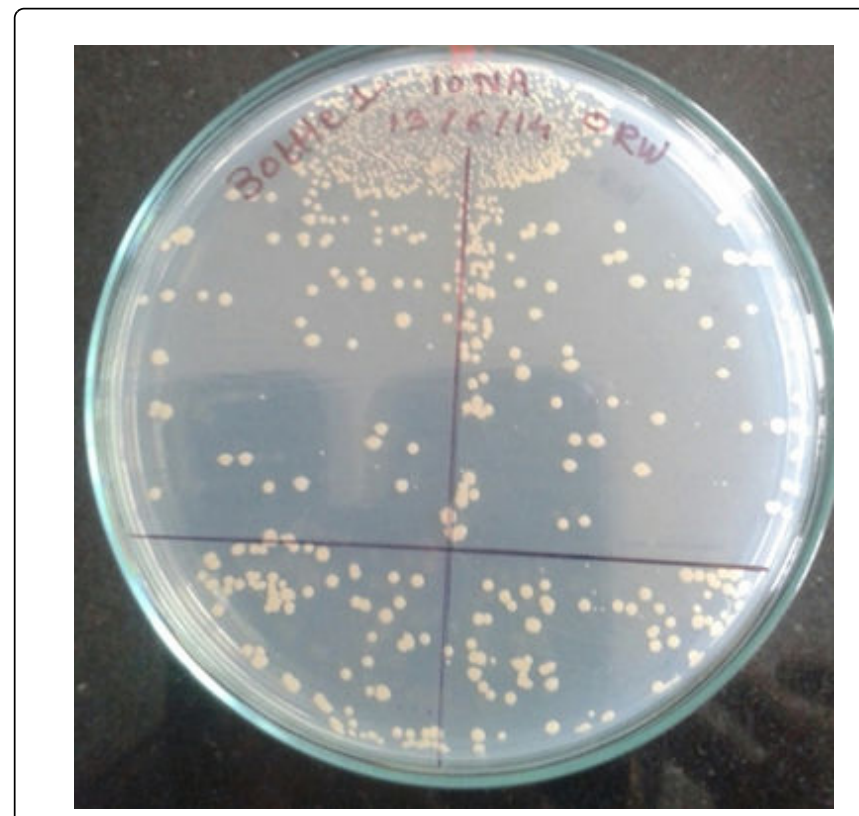

Figure 1: Growth of organisms after their enrichment on $10 \%$ Nutrient Agar.

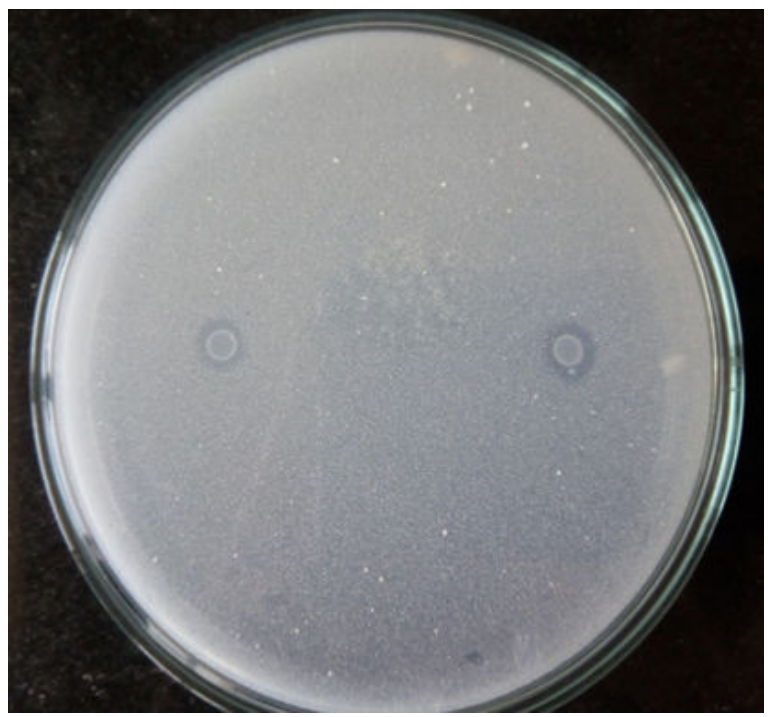

Figure 2: Isolates showing phosphate mobilization. 
Citation: Phale S (2018) Isolation and Screening of Multifunctional Plant Growth Promoting Rhizobacteria (PGPR) from Onion Rhizosphere (Allium cepa). J Bioprocess Biotech 8: 335. doi:10.4172/2155-9821.1000335

Page 3 of 4

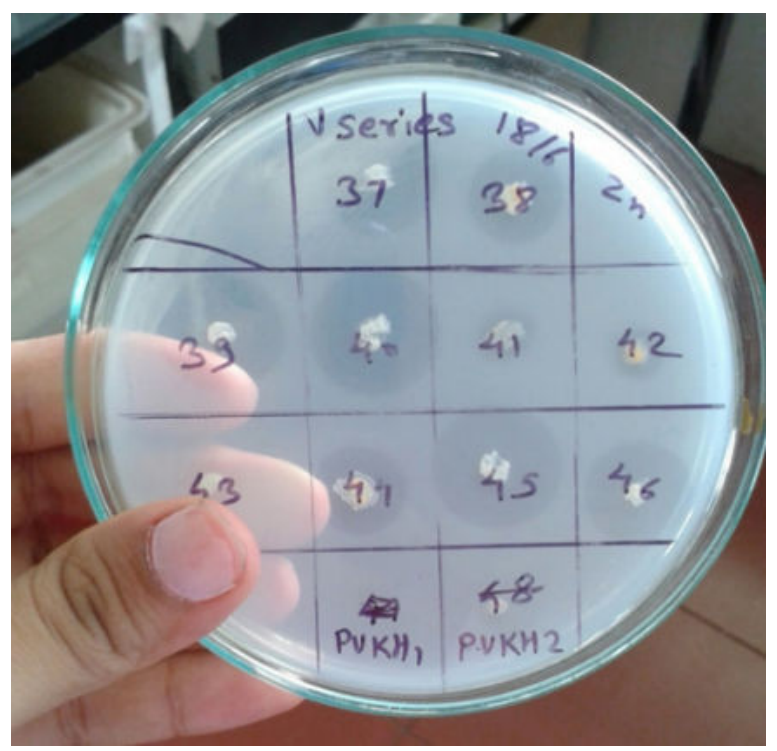

Figure 3: Isolates showing Zinc mobilization.

\begin{tabular}{|c|c|c|c|c|c|}
\hline Isolate No. & Phosphate mobilization & Zinc mobilization & Nitrogen fixation & Indole Acetic Acid Production & HCN gas Production \\
\hline Isolate 1 & + & + & + & + & - \\
\hline Isolate 3 & + & + & + & - & - \\
\hline Isolate 5 & + & + & + & + & - \\
\hline Isolate 14 & - & + & - & - & + \\
\hline Isolate 15 & + & + & + & + & + \\
\hline Isolate 22 & - & + & - & - & + \\
\hline Isolate 26 & - & + & - & + & + \\
\hline Isolate 27 & + & + & + & - & + \\
\hline Isolate 30 & - & + & + & - & - \\
\hline Isolate 31 & + & + & + & + & - \\
\hline Isolate 38 & + & + & + & - & - \\
\hline Isolate 44 & - & + & + & - & + \\
\hline Isolate 45 & + & + & - & - & - \\
\hline Isolate 46 & + & + & - & - & - \\
\hline
\end{tabular}

Table 3: Screening of isolates for Phosphate mobilization, Zinc mobilization, Nitrogen fixation, Indole Acetic Acid Production and HCN gas Production.

\section{Conclusion}

Undoubtedly there are numerous and complicated interaction that occur in the rhizosphere. High degrees of activity by both the plant roots and the microbial community are often difficult to conclusively

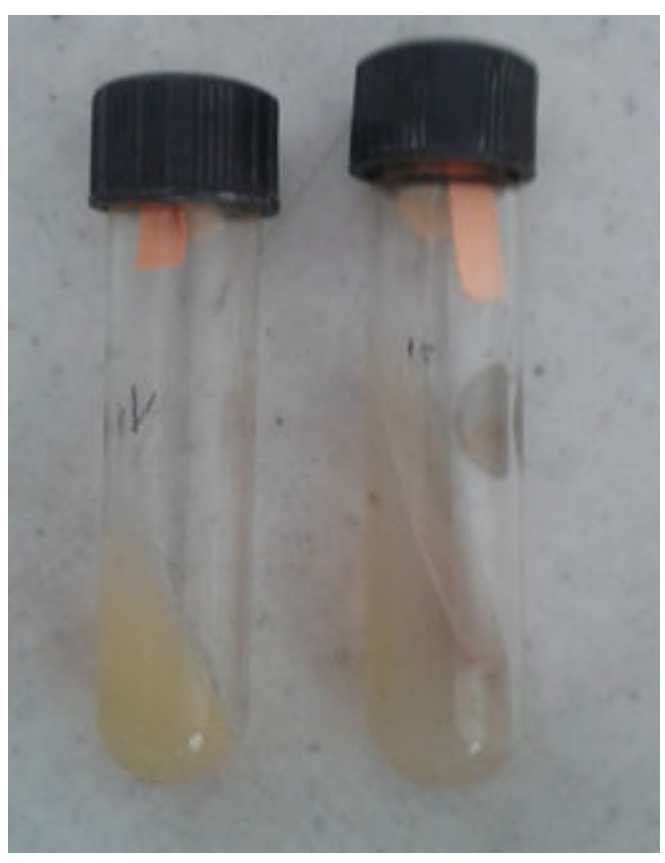

Figure 4: Isolates showing production of $\mathrm{HCN}$ gas. 
Citation: Phale S (2018) Isolation and Screening of Multifunctional Plant Growth Promoting Rhizobacteria (PGPR) from Onion Rhizosphere (Allium cepa). J Bioprocess Biotech 8: 335. doi:10.4172/2155-9821.1000335

Page 4 of 4

\section{References}

1. Marschner H (1995) Mineral nutrition of higher plants. 2nd edn. Academic Press, United States.

2. Hartmann A, Rothballer M, Schmid M (2008) Lorenz Hiltner, a pioneer in rhizosphere microbial ecology and soil bacteriology research. Plant Soil 312: 7-14
3. Normander B, Prosser JI (2000) Bacterial origin and community composition in the barley phytosphere as a function of habitat and presowing conditions. Appl Environ Microbiol 66: 4372-4377.

4. Cattelan AJ, Hartel PG, Fuhrmann JJ (1999) Screening for Plant GrowthPromoting Rhizobacteria to Promote Early Soybean Growth. Soil Sci Soc Am J 63: 1670-1680. 